\title{
Helicobacter pylori infection is identified as a cardiovascular risk factor in Central Africans
}

\author{
This article was published in the following Dove Press journal: \\ Vascular Health and Risk Management \\ 14 August 2012 \\ Number of times this article has been viewed
}

\section{Benjamin Longo-Mbenza' Jacqueline Nkondi Nsenga ${ }^{2}$ Etienne Mokondjimobe ${ }^{3}$ Thierry Gombet ${ }^{3}$ Itoua Ngaporo Assori ${ }^{3}$ Jean Rosaire Ibara ${ }^{3}$ Bertrand Ellenga-Mbolla ${ }^{3}$ Dieudonné Ngoma Vangu ${ }^{4}$ Simon Mbungu Fuele ${ }^{4}$ \\ 'Faculty of Health Sciences, Walter Sisulu University, Mthatha, South Africa; ${ }^{2}$ Division of Gastroenterology, University of Kinshasa, Kinshasa, Democratic Republic of the Congo; ${ }^{3}$ Faculty of Health Sciences, University of Marien Ngouabi, Brazzaville, Democratic Republic of the Congo; ${ }^{4}$ Biostatistics Unit, Lomo Medical Center, Limete, Kinshasa, Democratic Republic of the Congo}

Correspondence: Benjamin Longo-Mbenza Faculty of Health Sciences, Walter Sisulu University, Private Bag XI, Mthatha 5II7, Eastern Cape, South Africa

Tel +2 7732822843

Email longombenza@gmail.com
Background: Helicobacter pylori is now incriminated in the pathogenesis of atherosclerosis. Objective: To examine the importance of $H$. pylori infection as a cardiovascular disease (CVD) risk factor.

Methods: Two hundred five patients (128 with H. pylori infection [HP-seropositive] and 77 without) had a baseline assessment for other potential CVD risk factors and were followed prospectively for 10 years (1999-2008). They were assessed on a monthly basis for the outcomes of carotid plaque, angina pectoris, myocardial infarction, and stroke. In the HP-seropositive group, male sex and quartile 4 for IgG anti-H. pylori antibodies (anti-HP Ab) were correlated with traditional CVD risk factors, stroke, myocardial infarction, and angina pectoris.

Results: At the baseline assessment, the levels of carotid intima-media thickness, blood fibrinogen, total cholesterol, fasting plasma glucose, and uric acid were higher in $\mathrm{H}$. pyloriinfected patients than in the uninfected group. Serum HDL-cholesterol was significantly lower in the HP-seropositive group. Men had higher levels of IgG anti-HP Ab, waist circumference, blood pressure, uric acid, and total cholesterol than women. Within the HP-seropositive group, individuals in quartile 4 for IgG anti-HP Ab had higher rates of elevated fibrinogen, diabetes mellitus, low high-density lipoprotein cholesterol, arterial hypertension, and high total cholesterol than those in quartile 1. After adjusting for traditional CVD risk factors, $H$. pylori infection was the only independent predictor of incident carotid plaque (multivariate odds ratio $[\mathrm{OR}]=2.3,95 \%$ confidence interval $[\mathrm{CI}]: 1.2-7.2 ; P<0.0001$ ) and incident acute stroke (multivariate $\mathrm{OR}=3.6,95 \% \mathrm{CI}: 1.4-8.2 ; P<0.0001$ ). Within the HP-seropositive group and after adjusting for traditional CVD risk factors, male sex was the only independent predictor of incident angina pectoris (multivariate $\mathrm{OR}=3.5,95 \% \mathrm{CI}: 1.6-16 ; P<0.0001$ ), incident acute stroke (multivariate $\mathrm{OR}=3.2,95 \% \mathrm{CI}: 1.4-28 ; P<0.0001$ ), and acute myocardial infarction (multivariate $\mathrm{OR}=7.2,95 \% \mathrm{CI}: 3.1-18 ; P<0.0001$ ).

Conclusion: Our study provides evidence for an association among known CVD risk factors, carotid plaque, stroke, and $H$. pylori infection. Among infected individuals, there is a significant association among severity of HP-seropositivity, male sex, and CVD. The eradication of $H$. pylori infection may therefore reduce the emerging burden of CVD in Africa.

Keywords: Helicobacter pylori, stroke, myocardial infarction, cardiovascular disease, carotid plaque, Africans

\section{Introduction}

Cardiovascular diseases (CVDs, including coronary artery disease, stroke, and peripheral vascular disease) are the leading causes of morbidity and mortality in Western and developed countries. ${ }^{1-3}$ Almost half the disease burden in developing countries is already due to noncommunicable diseases, including CVD. ${ }^{3}$ 
In sub-Saharan Africa (SSA), the INTERHEART Africa Study reports that traditional CVD risk factors (smoking, diabetes mellitus, hypertension, abdominal obesity, and ratio of apolipoprotein B to apolipoprotein A-1) account for almost $90 \%$ of myocardial infarction, ${ }^{4}$ which is consistent with the overall INTERHEART study. ${ }^{5}$ This has fostered the search for additional, nontraditional risk factors or risk factor equivalents for CVD among black Africans with low prevalence of coronary artery disease. ${ }^{6}$

Furthermore, the absence of traditional and known risk factors does not totally protect Central Africans from CVD. ${ }^{7,8}$ Consistent with many studies from the literature, ${ }^{9-12}$ we reported that Helicobacter pylori infection, one of the new CVD risk factors, has been epidemiologically linked to metabolic syndrome and established CVD. ${ }^{13,14}$ However, the predictive role of $H$. pylori infection in CVD is still a matter of debate, ${ }^{15}$ and that of the interaction between infection and sex is unknown in our setting.

In Central Africans with low serum triglycerides, H. pylori seropositivity per se might generate CVD both in general and particularly in men with $H$. pylori infection. ${ }^{13}$ A causal association between $H$. pylori infection and CVD would be of major health importance in SSA countries, such as Democratic Republic of the Congo, because the infection can be evaluated and eradicated with first-, second-, and third-line eradication therapy (proton-pump inhibitors + amoxicillin + clarithromycin, and others), ${ }^{16}$ which showed prevention of cardiometabolic risk in our previous study ${ }^{13}$ and in Italy. ${ }^{17}$

The aim of our study, therefore, was to evaluate potential cross-sectional and prospective associations between $H$. pylori seropositivity and CVD risk factors in a screening population, as well as to investigate a prospective association between sex and CVD among participants with $H$. pylori seropositivity.

\section{Methods}

After the study design (Figure 1) was approved by the ethical committee of the Lomo Medical Center, 205 patients (128 with H. pylori infection [HP-seropositive], 77 without [HP-seronegative]) had a baseline assessment for other potential CVD risk factors in 1999 and had monthly follow-up at the Lomo Medical Center for 10 years until 2008. A questionnaire, electrocardiogram (ECG), enzymes, neurological exam, and carotid ultrasonography were completed at the baseline assessment, at the onset of any acute CVD event, and at the final evaluation (mean time between baseline and conclusion of follow-up $=9.6 \pm 0.8$ years).
At the baseline examination, participants were not suffering from CVD, gastric ulcer, chronic infection, or cancer. HP-seropositives and HP-seronegatives were matched for the following CVD risk factors: sex, age, smoking, alcohol intake, body mass index (BMI), waist circumference, heart rate, systolic blood pressure (SBP), diastolic blood pressure (DBP), fasting plasma glucose (FPG), and leukocytes. Further, serum total cholesterol, high-density lipoprotein cholesterol (HDL-cholesterol), low-density lipoprotein cholesterol (LDL-cholesterol), triglycerides, fibrinogen, intima-media thickness (IMT), arterial hypertension, diabetes mellitus, socioeconomic status, and residence were assessed on a monthly basis for the outcomes of peripheral vascular disease, angina pectoris, myocardial infarction, and stroke within the Division of Cardiology at the Lomo Medical Center, Kinshasa, Limete, Democratic Republic of the Congo.

A structured and standardized questionnaire consisted of demographic information; past, current and future medical history; and a systematic review of symptoms, including acute chest pain and CVD.

All participants underwent $\mathrm{ECG}^{18}$ and physical measurements ${ }^{19}$ by trained medical doctors and registered nurses.

Outpatients wore light clothes during measurements of body weight to the nearest $100 \mathrm{~g}$ using calibrated scales, height with bare feet to the nearest $\mathrm{mm}$, waist circumference in duplicate at the level midway between the lowest rib margin and the iliac crest, and hip circumference at the widest trochanters to the nearest $\mathrm{mm}$; the mean values of circumferences were used in analysis. BMI was calculated as weight $(\mathrm{kg})$ divided by height squared $\left(\mathrm{m}^{2}\right)$.

Blood pressure (BP) and heart rate were recorded using an Omron HEM 705 electronic BP manometer (Omron Life Science Co, Ltd, Tokyo, Japan) after the patient rested for 5 minutes. BP and heart rate were taken three times on the left arm in the supine position at the level of the heart, by the same trained physician (BLM), following the World Health Organization (WHO) guidelines. ${ }^{20}$

\section{Laboratory analyses}

Blood samples were drawn between 08:00 and 10:00 after a 12-hour fast and 30 minutes of rest. All laboratory specimens were analyzed by the same technician from Lomo Medical Center. Blood was assayed for standard leukocyte count, glucose, fibrinogen, and H. pylori seropositivity. Fibrinogenemia was measured using the electromagnetic water-bath method and bioMérieux Fibriquick kit (bioMérieux, Marcy l'Etoile, France), based on the Clauss method (normal 


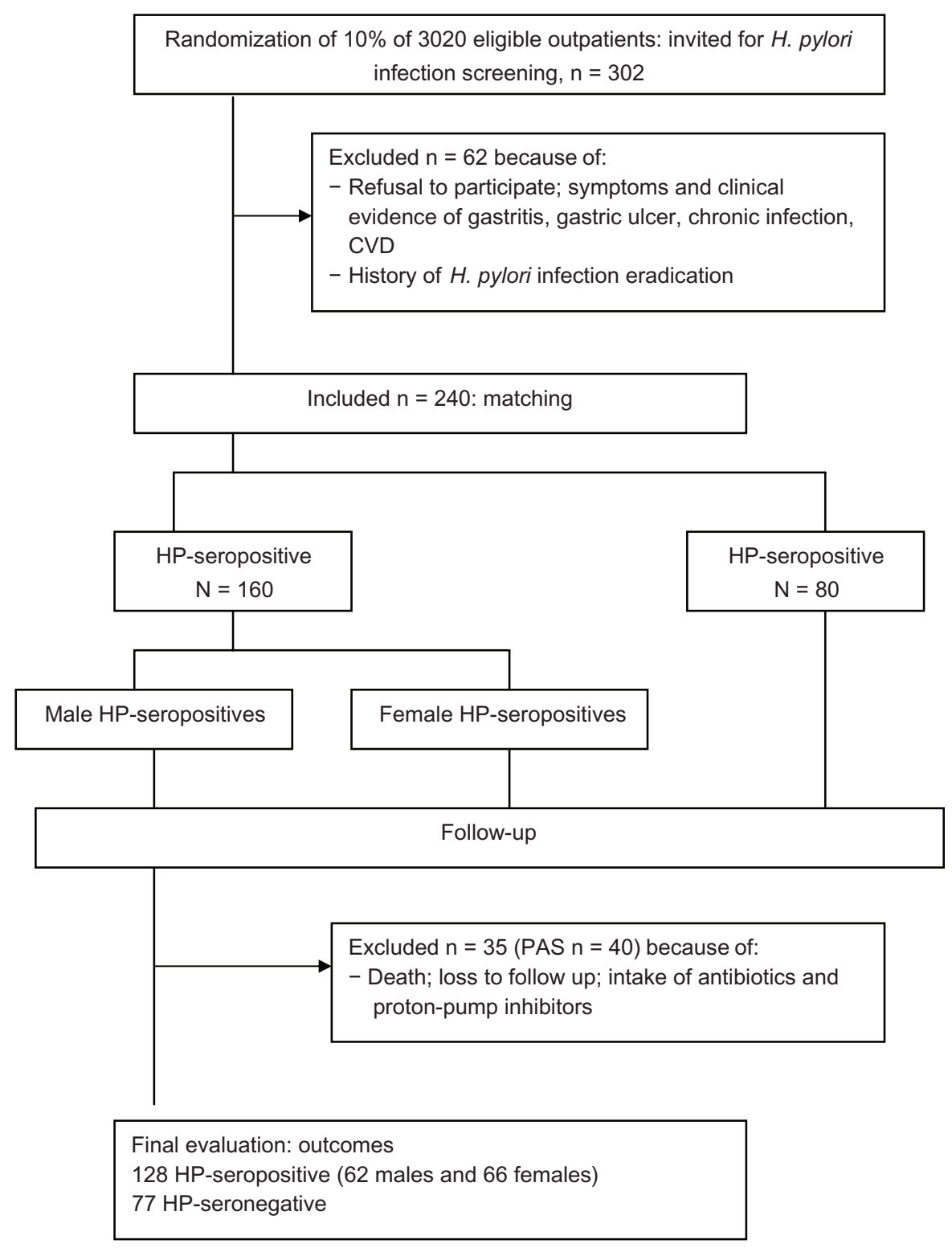

Figure I Flow chart of the study.

Abbreviations: HP, Heliocobacter pylori (H. pylori).

range $=1.8-4 \mathrm{~g} / \mathrm{L})$. FPG was determined using the glucose oxidase method (Boehringer, Mannheim, Germany).

Immunoglobulin $\mathrm{G}$ ( $\mathrm{IgG}$ ) antibodies to $H$. pylori (anti-HP Ab) were measured by a commercial enzymelinked immunosorbent assay (Pyloriset ${ }^{\circledR}$ EIA-G; Orion Diagnostica, Espoo, Finland) by linear regression analysis. The sensitivity and specificity of the assay were higher than $95 \%$. The range of serum levels of anti-HP Ab was between $100 \mathrm{U}$ and $12,800 \mathrm{U}$.

\section{Carotid ultrasonography}

A single certified sonographer (BLM) performed the carotid B-mode ultrasound imaging using a Biosound Phase Two ultrasonography device equipped with a $7.5 \mathrm{Mhz}$ annular array probe (Biosound Inc, Indianapolis, IN). This B-mode ultrasound imaging protocol was designed to ensure a valid and reliable identification of arterial carotid references and the definition of near and far wall interfaces. Because the bifurcations and not the common carotids are a preferential site for atherosclerosis, ${ }^{20}$ we measured IMT at both these sites. ${ }^{21}$ The key anatomical features defining these segments were the proximal origin of the bulb and the tip of the flow divider that separated internal from external carotid arteries. In longitudinal artery images, two main interfaces, corresponding to specific anatomical boundaries, were associated to the scanning and reading protocol described 
by Bond et al. ${ }^{22}$ Scans from all outpatients were read by the same reader without knowledge of $H$. pylori seropositivity. A random sample of outpatients (10\%) was selected for a repeat examination to determine intravariability (methodological reproducibility). Mean maximum IMT was calculated as the mean of the maximum IMT detected in the far walls of up to six carotid artery segments. The mean of the maximum IMT of the common and bifurcation far walls and the single maximum IMT were also calculated. Intrareader Pearson's correlation coefficients for these three measurements were $0.871,0.908$, and 0.746 , respectively.

\section{Definitions}

Dyslipidemia (elevated total cholesterol and low HDLcholesterol) and diabetes mellitus were defined from medical records.

H. pylori infection was defined as IgG anti-HP $\mathrm{Ab}>300 \mathrm{U}$. Hypertension was defined both by medical history and treatment of arterial hypertension and by criteria for arterial hypertension, such as SBP $>140 \mathrm{mmHg}$ or DBP $>90 \mathrm{mmHg}$, according to $\mathrm{WHO} /$ International Society of Hypertension guidelines. $.^{20} \mathrm{BMI} \geq 25 \mathrm{~kg} / \mathrm{m}^{2}$ was a criterion for overweight/obesity. ${ }^{23}$ Carotid plaques were characterized by carotid artery thickening $>1.3 \mathrm{~mm}^{24}$

\section{Statistical analysis}

Data were expressed as mean \pm standard deviation (SD) or percentages. The significance of differences was determined using the unpaired Student's $t$-test when comparing baseline continuous data. The Chi-square test was used for comparing percentages of categorical data. IgG anti-HP Ab, hypertension, diabetes, obesity, lipid profile, smoking, alcohol intake, age, SBP, DBP, leukocyte count, sex, FPG, IMT, and fibrinogen were incorporated as explanatory variables in the logistic regression. Therefore, after adjusting for confounders, the relationship of angina pectoris, acute myocardial infarction, acute stroke, and carotid plaque as dependent variables was analyzed separately in the global study population and in the patients with $H$. pylori infection. The required significance level for tests was set at a $P$ value $<0.05$. Statistical analysis was performed using the SPSS package for Windows (version 18; SPSS Inc, Chicago, IL). ${ }^{25}$

\section{Results}

A total of 205 black urban Congolese individuals were enrolled in this study (response rate of $85.4 \%$ out of 240 people included). Among 35 patients excluded at the final examination, 20 had died, 10 were lost to follow-up and five were excluded for medication intake. They were divided into two groups according to $H$. pylori seropositivity, classified as either HPseropositive $(n=128)$ or HP-seronegative $(n=77)$.

At baseline examination, there was a significant association among elevated values of carotid artery IMT, blood fibrinogen, total cholesterol, FPG, and uric acid; lower levels of HDL-cholesterol; and $H$. pylori seropositivity (Table 1). As expected, the mean values of age, BMI, waist circumference, heart rate, SBP, DBP, and leukocyte count in HP-seropositives were similar $(P>0.05)$ to those in HP-seronegatives. The mean values of triglycerides and LDL-cholesterol were similarly low in the two groups.

Table I Comparison of studied parameters in participants with and without $H$. pylori infection at the baseline examination

\begin{tabular}{|c|c|c|c|}
\hline Variables of interest & $\begin{array}{l}\text { With H. pylori } \\
\text { infection }(n=128)\end{array}$ & $\begin{array}{l}\text { Without } H \text {. pylori } \\
\text { infection }(n=77)\end{array}$ & $P$-value \\
\hline Age (years) & $53.4 \pm 12.9$ & $52.5 \pm 16.6$ & NS \\
\hline BMI $\left(\mathrm{kg} / \mathrm{m}^{2}\right)$ & $26.4 \pm 4.9$ & $24.9 \pm 5.4$ & NS \\
\hline Waist circumference $(\mathrm{cm})$ & $101.9 \pm 11.4$ & $98.7 \pm 16.1$ & NS \\
\hline Heart rate/minute & $78.3 \pm 14.3$ & $76.9 \pm 14.6$ & NS \\
\hline $\mathrm{SBP}(\mathrm{mmHg})$ & $159.9 \pm 36.8$ & $153.4 \pm 34.4$ & NS \\
\hline $\mathrm{DBP}(\mathrm{mmHg})$ & $92 \pm 20.9$ & $90.8 \pm 19.5$ & NS \\
\hline Leukocytes $/ \mathrm{mm}^{3}$ & $6.3 \times 10^{3} \pm 2.4 \times 10^{3}$ & $5.9 \times 10^{3} \pm 2.5 \times 10^{3}$ & NS \\
\hline Fibrinogen (mg/dL) & $471.5 \pm 23.6$ & $297.2 \pm 14.7$ & $<0.000$ I \\
\hline IMT, carotid artery $(\mathrm{mm})$ & $0.8 \pm 0.1$ & $0.6 \pm$ & $<0.000$ I \\
\hline Total cholesterol (mg/dL) & $216.4 \pm 43.6$ & $173.3 \pm 38.9$ & $<0.01$ \\
\hline Triglycerides (mg/dL) & $100.5 \pm 32.1$ & $98.4 \pm 34.4$ & NS \\
\hline LDL-cholesterol (mg/dL) & $102.3 \pm 8.5$ & $101.1 \pm 15.1$ & NS \\
\hline HDL-cholesterol (mg/dL) & $56.8 \pm 21.2$ & $96.4 \pm 21.3$ & $<0.01$ \\
\hline Fasting plasma glucose $(\mathrm{mg} / \mathrm{dL})$ & $106.6 \pm 41.2$ & $84 \pm 15$ & $<0.01$ \\
\hline Uric acid $(\mathrm{mg} / \mathrm{dL})$ & $15.2 \pm 1.7$ & $5.1 \pm 2$ & $<0.000$ I \\
\hline
\end{tabular}

Abbreviations: H. pylori, Helicobacter pylori; BMI, body mass index; SBP, systolic blood pressure; DBP, diastolic blood pressure; IMT, intima media thickness; LDL, low-density lipoprotein; HDL, high-density lipoprotein, NS, nonsignificant. 
At baseline examination, the HP-seropositive group and the HP-seronegative group had similar rates of cigarette smoking, alcohol intake, diabetes mellitus, and arterial hypertension (Table 2). When sex was taken into account at the baseline assessment, men had significantly higher levels of IgG anti-HP Ab, waist circumference, SBP, DBP, uric acid, and total cholesterol than women (Table 3). However, age, BMI, FPG, HDL-cholesterol, fibrinogen, and LDLcholesterol did not vary $(P>0.05)$ between males and females.

In the HP-seropositive group at the baseline check-up, there was a significant association among increases in rates of elevated fibrinogen, diabetes mellitus, low HDL-cholesterol, elevated total cholesterol, arterial hypertension, and severity of HP-seropositivity by comparing quartile 4 for IgG anti-HP Ab with quartile 1 (Table 4).

\section{Final evaluation for all participants}

At the end of the follow-up, 60 participants (29.3\%) had developed carotid plaques $(35.2 \%, \mathrm{n}=45$ in HP-seropositives vs $19.5 \%, \mathrm{n}=15$ in HP-seronegatives; $P<0.0001)$, and 36 participants $(17.6 \%)$ had experienced acute stroke $(23.4 \%, \mathrm{n}=30$ in HP-seropositives vs $7.8 \%$, $\mathrm{n}=6$ in HP-seronegatives; $P<0.0001$ ).

After adjusting for traditional risk factors, only HPseropositivity was identified as a significant and independent predictor of incident carotid plaque (multivariate-adjusted odds ratio $[\mathrm{OR}]=2.3,95 \%$ confidence interval $[\mathrm{CI}]$ : $1.2-7.2 ; P<0.0001)$ in logistic regression model 1, as well as a significant and independent predictor of incident acute stroke (multivariate-adjusted $\mathrm{OR}=3.6,95 \% \mathrm{CI}: 1.4-8.2$; $P<0.0001)$ in logistic regression model 2.

\section{Final evaluation for the HP-seropositive group}

Among HP-seropositives, the incident CVD events were angina pectoris, estimated $21.9 \%(n=28: 32.3 \%, n=20$ in

Table 2 Traditional risk factors in all participants according to $H$. pylori serologic status

\begin{tabular}{|c|c|c|c|}
\hline $\begin{array}{l}\text { Variables of } \\
\text { interest }\end{array}$ & $\begin{array}{l}\text { With } H . \text { pylori } \\
\text { infection } \\
(n=I 28) \\
n(\%)\end{array}$ & $\begin{array}{l}\text { Without } H \text {. pylori } \\
\text { infection } \\
(n=77) \\
n(\%)\end{array}$ & $P$-value \\
\hline Cigarette smoking & $21(16.6)$ & $12(15.6)$ & NS \\
\hline Alcohol intake & $19(14.9)$ & II (I4.3) & NS \\
\hline Diabetes mellitus & $13(10.2)$ & $8(10.4)$ & NS \\
\hline Arterial hypertension & $30(23.4)$ & $18(23.3)$ & NS \\
\hline
\end{tabular}

Abbreviations: NS, nonsignificant; $H$. pylori, Helicobacter pylori.
Table 3 Mean values of continuous data for known indicators of CVD risk according to sex

\begin{tabular}{|c|c|c|c|}
\hline Variables of interest & $\begin{array}{l}\text { Men } \\
\text { mean } \pm \text { SD }\end{array}$ & $\begin{array}{l}\text { Women } \\
\text { mean } \pm \text { SD }\end{array}$ & $P$-value \\
\hline $\lg G$ antibodi & $2475 \pm 362$ & $1246 \pm 126$ & $<0.0001$ \\
\hline \multicolumn{4}{|l|}{ H. pylori (U) } \\
\hline Age (years) & $52 \pm 12$ & $53 \pm 15$ & NS \\
\hline BMI $\left(\mathrm{kg} / \mathrm{m}^{2}\right)$ & $27.4 \pm 5.1$ & $26.4 \pm 5.1$ & NS \\
\hline Waist circumference $(\mathrm{cm})$ & $99.6 \pm 12.8$ & $90.3 \pm 15.1$ & $<0.05$ \\
\hline $\mathrm{SBP}(\mathrm{mmHg})$ & $169.2 \pm 30.1$ & $147.7 \pm 39.9$ & $<0.01$ \\
\hline $\mathrm{DBP}(\mathrm{mmHg})$ & $98.8 \pm 18.6$ & $81.9 \pm 21.2$ & $<0.0001$ \\
\hline Uric acid (mg/dL) & $11.6 \pm 3.4$ & $5.7 \pm 1.9$ & $<0.01$ \\
\hline $\begin{array}{l}\text { Fasting plasma glucose } \\
(\mathrm{mg} / \mathrm{dL})\end{array}$ & $111 \pm 42$ & $99.4 \pm 35.2$ & NS \\
\hline Total cholesterol (mg/dL) & $218.7 \pm 83.2$ & $182.3 \pm 63.6$ & $<0.01$ \\
\hline HDL-cholesterol (mg/dL) & $62.2 \pm 26.8$ & $60.8 \pm 32.3$ & NS \\
\hline Fibrinogen (mg/dL) & $477.6 \pm 22.6$ & $466.3 \pm 25.4$ & NS \\
\hline LDL-cholesterol (mg/dL) & $101 \pm 28$ & $100.5 \pm 29.6$ & NS \\
\hline
\end{tabular}

Abbreviations: CVD, cardiovascular disease; SD, standard deviation; IgG, immunoglobulin G; H. pylori, Helicobacter pylori; BMI, body mass index; SBP, systolic blood pressure; DBP, diastolic blood pressure; HDL, high-density lipoprotein; LDL, low-density lipoprotein.

men vs $12.1 \%, \mathrm{n}=8$ in women; $P<0.0001)$; acute myocardial infarction, estimated 25\% $(\mathrm{n}=32: 41.9 \%$, $\mathrm{n}=26$ in men vs $9.1 \%, \mathrm{n}=6$ in women; $P<0.0001$ ); and acute stroke, estimated $14.1 \%(\mathrm{n}=18: 21 \%, \mathrm{n}=13$ in men vs $7.6 \%, \mathrm{n}=5$ in women; $P<0.0001$ ).

After adjusting for traditional risk factors, male HPseropositives developed a higher risk of incidence of angina pectoris (multivariate-adjusted $\mathrm{OR}=3.5,95 \% \mathrm{CI}$ : $1.6-16$; $P<0.0001$ ), acute stroke (multivariate-adjusted $\mathrm{OR}=3.2$, 95\% CI: $1.4-28 ; P<0.0001)$, and acute myocardial infarction (multivariate-adjusted $\mathrm{OR}=7.2,95 \% \mathrm{CI}$ : $3.1-18$; $P<0.0001$ ), respectively, in logistic regression models 3 , 4 , and 5 .

\section{Discussion}

To the best of our knowledge, this is the first study clarifying the importance of HP-seropositivity to CVD risk in

Table 4 Traditional risk factors by quartiles for lgG anti-HP Ab in individuals seropositive for $H$. pylori

\begin{tabular}{|c|c|c|c|}
\hline \multirow[t]{3}{*}{ Variables of interest } & $\begin{array}{l}\text { Quartile } 4 \\
n=32\end{array}$ & $\begin{array}{l}\text { Quartile I } \\
\mathrm{n}=\mathbf{3 2}\end{array}$ & \multirow[t]{3}{*}{$P$-value } \\
\hline & \multicolumn{2}{|c|}{ For IgG anti-HP Ab } & \\
\hline & n (\%) & n (\%) & \\
\hline Elevated fibrinogen & $9(28.1)$ & $3(10)$ & $<0.001$ \\
\hline Diabetes mellitus & $7(21.9)$ & $2(6.3)$ & $<0.001$ \\
\hline Low HDL-cholesterol & $9(28.1)$ & $\mathrm{I}(3.1)$ & $<0.000$ I \\
\hline Elevated total cholesterol & $16(50)$ & $9(28.1)$ & $<0.000$ I \\
\hline Arterial hypertension & $26(81.3)$ & $19(59.4)$ & $<0.001$ \\
\hline
\end{tabular}

Abbreviations: IgG anti-HP Ab, immunoglobulin $\mathrm{G}$ antibodies against $H$. pylori, Helicobacter pylori; HDL, high-density lipoprotein. 
asymptomatic Central Africans. In HP-seropositives, the association between male sex and CVD was also shown in this study.

The present data on CVD and its traditional risk factors confirm the rapidly changing epidemiologic and clinical spectrum of noncommunicable diseases in SSA in general and in urban areas in particular. ${ }^{4-8,26,27}$

The present findings demonstrated that $H$. pylori infection is significantly associated with male sex; with high levels of fibrinogen, total cholesterol, uric acid, and FPG; and with low HDL-cholesterol, as reported by other studies. ${ }^{12-14,17}$ However, this study did not confirm significant associations between high LDL-cholesterol and $H$. pylori infection ${ }^{12}$ or between triglycerides and $H$. pylori infection. ${ }^{11}$ Akbas et al reported that there is no significant difference in serum HDLcholesterol, LDL-cholesterol, or total cholesterol between HP-seropositives and HP-seronegatives. ${ }^{11}$

In all participants, seropositivity for IgG anti-HP Ab was significantly related to incident carotid plaques and acute stroke, but neither to angina pectoris nor to acute myocardial infarction. The group's young average age and a lipid profile within the normal range may explain the absence of coronary vessel dysfunction. ${ }^{28} \mathrm{H}$. pylori infection could be linked to the early stages of coronary atherosclerosis rather than advanced coronary atherosclerosis. ${ }^{29}$ Stroke is commoner than coronary heart disease in Africans with severe and uncontrolled hypertension. ${ }^{7}$ Progression of carotid lesions already associated with $H$. pylori infection may explain the onset of carotid plaques and stroke ${ }^{30}$ in this screening population. However, carotid atherosclerosis is not related to $H$. pylori infection in the United Kingdom, ${ }^{31}$ whereas HP-seropositivity is associated with carotid plaques and cerebrovascular and cardiovascular events in Italy. ${ }^{32}$

Our data clearly demonstrate that severity of $H$. pylori infection was significantly associated with the most important traditional risk factors for CVD, such as diabetes mellitus, arterial hypertension, high levels of serum fibrinogen and total cholesterol, and low HDL-cholesterol. In these HPseropositives, male sex was the only independent predictor of both cerebrovascular and coronary heart diseases. H. pylori infection showed an extremely broad spectrum of disease outcomes. These findings lend support to the notion that chronic $H$. pylori infection with exacerbation of inflammation (elevated fibrinogen), male sex (smoking) and dyslipidemia may contribute to early onset of atherosclerosis ${ }^{33,34}$ in those Africans facing demographic transition. Severity of HPseropositivity in this infected group may reflect virulent strains bearing the cytotoxin-associated protein (CagA), with changes in inflammatory markers and higher risk of myocardial infarction..$^{10,35}$

\section{Clinical implications}

Our results will have clinical and public health implications for the prevention, detection and eradication of $H$. pylori infection. These strategies may reduce the burden of CVD and its associated high costs, morbidity and mortality.

Considerable evidence suggests that ultrasonic measurements of early atherosclerosis are clinically significant. It remains unclear what causes the chronic inflammatory state within carotid plaque. Action of $H$. pylori bacteria either directly on vascular cells or via the indirect effects of cytokines and acute-phase proteins at nonvascular sites may be incriminated in this accelerated atherosclerosis..$^{35,36}$

\section{Study limitations}

Dependence on only serological evidence for presence of H. pylori infection; small sample size; and lack of markers, such as C-reactive protein, PON-1, and Cag, could be the limitations of this study. Its strength, however, is its prospective design with suitable adjustments for confounding factors.

\section{Conclusion}

CVD and its traditional risk factors are emerging as public problems among Central Africans.

In general, $H$. pylori infection may contribute to high risk of carotid plaque and stroke by its relationship with traditional CVD risk factors.

In the HP-seropositive group, very high levels of $\mathrm{IgG}$ anti-HP Ab are significantly associated with traditional CVD risk factors, while men are at higher risk of angina pectoris, stroke, and myocardial infarction than women.

\section{Disclosure}

The authors report no conflicts of interest in this work.

\section{References}

1. World Health Organization. Preventing Chronic Diseases: A vital investment. Geneva, Switzerland: WHO; 2005.

2. World Health Organization. The World Health Report 2002: Reducing Risks, Promoting Healthy Life. Geneva, Switzerland: WHO; 2002.

3. Lopez AD, Mathers CD, Ezzati M, Jamison DT, Murray CJ. Global and regional burden of disease and risk factors, 2001: systematic analysis of population health data. Lancet. 2006;367:1747-1757.

4. Steyn K, Sliwa K, Hawken S, et al. Risk factors associated with myocardial infarction in Africa: the INTERHEART Africa study. Circulation. 2005;112:3554-3561.

5. Yusu S, Hawken S, Ounpuu S, et al; for INTERHEART Study Investigators. Effect of potentially modifiable risk factors associated with myocardial infarction in 52 countries (the INTERHEART study): case-control study. Lancet. 2004;364:937-952. 
6. Walker AR, Sareli P. Coronary heart disease: outlook for Africa. $J R$ Soc Med. 1997;90:23-27.

7. Longo-Mbenza B, Luila EL, Mbete P, Vita EK. Is hyperuricemia a risk factor of stroke and coronary heart disease among Africans? Int $J$ Cardiol. 1999;71(1):17-22.

8. Longo-Mbenza B, Tonduangu K, Muyeno K, et al. Predictors of stroke-associated mortality in Africans. Rev Epidemiol Sante Publique. 2000;48(1):31-39.

9. Rajasekhar D, Subramanyam G, Latheef SA, Vanajakshamma V, Srilatha A, Chaudhury A. Infectious aetiology in acute coronary syndromes. Indian J Med Microbiol. 2002;20(2):83-87.

10. Khodaii Z, Vakili H, Ghaderian SM, Najar RA, Panah AS. Association of Helicobacter pylori infection with acute myocardial infarction. Coron Artery Dis. 2011;22(1):6-11.

11. Akbas HS, Basyigit S, Suleymanlar I, Kemaloglu D, et al. The assessment of carotid intima media thickness and serum paraoxonase-1 activity in Helicobacter pylori positive subjects. Lipids Health Dis. 2010;9:92.

12. Satoh H, Saijo Y, Yoshioka E, Tsutsui H. Helicobacter pylori infection is a significant risk for modified lipid profile in Japanese male subjects. J Atheroscler Thromb. 2010;17(10):1041-1048.

13. Longo-Mbenza B, Nkondi Nsenga J, Vangu Ngoma D. Prevention of the metabolic syndrome insulin resistance and the atherosclerosis diseases in Africans infected by Helicobacter pylori infection and treated by antibiotics. Int J Cardiol. 2007;121:229-238.

14. Longo-Mbenza B, Mambune HF, Kasiam JB, et al. Relationship between waist circumference and cholesterol in Central Africans with congestive heart failure. West Afr J Med. 2007;26:183-190.

15. Christodoulou DK, Milionis HJ, Pappa P, et al. Association of Helicobacter pylori infection with cardiovascular disease - is it just a myth? Eur J Intern Med. 2011;22:191-194.

16. Suzuki H, Nishizawa T, Hibi T. Helicobacter pylori eradication therapy. Future Virol. 2010;5:639-648.

17. Pellicano R, Oliaro E, Fagoonee S, et al. Clinical and biochemical parameters related to cardiovascular disease after Helicobacter pylori eradication. Int Angiol. 2009;28:469-473.

18. Prineas RJ, Crow RS, Blackburn H. The Minnesota Code Manual of Electrocardiographic Findings. Bristol, UK: John Wright; 1982.

19. World Health Organization. Measuring Obesity: Classification and description of anthropometric data. Copenhagen, Denmark: WHO; 1989.

20. Guidelines Subcommittee, 1999 WHO. International Society of Hypertension guidelines for the management of hypertension. J Hypertens. 1999; 17:151-183.

21. Tang R, Hennig M, Thomasson B, et al. Baseline reproducibility of B-mode ultrasonic measurement of carotid artery intima-media thickness: the European Lacidipine Study on Atherosclerosis (ELSA). J Hypertens. 2000;18:197-201.
22. Bond MG, Wilmoth SK, Enevold GL, Strickland HL. Detection and monitoring of asymptomatic atherosclerosis in clinical trials. Am J Med. 1989;86:33-36.

23. Molarius A, Seidell JC, Sana S, Tuomilehto J, Kuulasmaa K. Varying sensitivity of waist action levels to identify subjects with overweight or obesity in 19 populations of the WHO MONICA project. J Clin Epidemiol. 1999;52:1213-1224.

24. Zanchette A, Bond MG, Hennig M, et al. Risk factors associated with alterations in carotid intima-media thickness in hypertension: baseline data from the European Lacidipine Study on Atherosclerosis J Hypertens. 1998;16:949-961.

25. University of Bristol Information Services. Introduction to SPSS (version 18) for Windows. Practical workbook. Available from: http:// www.bristol.ac.uk/it-services/learning/documentation/spss18-2/spss8-2t.pdf. Accessed December 12, 2011

26. World Health Organization Regional Office for Africa. Noncommunicable Diseases: A Strategy for the African region. Harare, Zimbabwe: WHO; 2000.

27. Akinboboye O, Idris O, Akinboboye O, Akinkugbe O. Trends in coronary artery disease and associated risk factors in sub-Saharan Africans. J Hum Hypertens. 2003;17:381-387.

28. Khairy P, Rinfret S, Tardif JC, et al. Absence of association between infectious agents and endothelial function in healthy young men. Circulation. 2003;107:1966-1971.

29. Park MJ, Choi SH, Kim D, et al. Association between Helicobacter pylori seropositivity and the coronary artery calcium score in a screening population. Gut Liver. 2011;5(3):321-327.

30. Corrado E, Rizzo M, Tantillo R, et al. Markers of inflammation and infection influence the outcome of patients with baseline asymptomatic carotid lesions: a 5-year follow-up study. Stroke. 2006;37:482-486.

31. Mayr M, Kiechl S, Tsimikas S, et al. Oxidized low-density lipoprotein autoantibodies, chronic infections, and carotid atherosclerosis in a population-based study. J Am Coll Cardiol. 2006;47(12):2436-2443.

32. Spence JD, Norris J. Infection, inflammation, and atherosclerosis Stroke. 2003;34:333-334.

33. Marra M, Bonfigli AR, Bonazzi P, et al. Asymptomatic Helicobacter pylori infection increases asymmetric dimethylarginine levels in healthy subjects. Helicobacter. 2005;10(6):609-614.

34. Elkind MS, Luna JM, Moon YP, et al. Infectious burden and carotid plaque thickness: the northern Manhattan study. Stroke. 2010;41(3): e117-e122.

35. Suzuki H, Matsuzaki J, Hibi T. Lifestyle-related diseases and H. pylori. Nihon Rinsho. 2009;67(12):2366-2371.

36. Nazmi A, Diez-Roux AV, Jenny NS, Tsai MY, Szklo M, Aiello AE. The influence of persistent pathogens on circulating levels of inflammatory markers: a cross-sectional analysis from the Multi-Ethnic Study of Atherosclerosis. BMC Public Health. 2010;10:706.
Vascular Health and Risk Management

\section{Publish your work in this journal}

Vascular Health and Risk Management is an international, peerreviewed journal of therapeutics and risk management, focusing on concise rapid reporting of clinical studies on the processes involved in the maintenance of vascular health; the monitoring, prevention and treatment of vascular disease and its sequelae; and the involvement of

\section{Dovepress}

metabolic disorders, particularly diabetes. This journal is indexed on PubMed Central and MedLine. The manuscript management system is completely online and includes a very quick and fair peer-review system, which is all easy to use. Visit http://www.dovepress.com/ testimonials.php to read real quotes from published authors. 